SHORT REPORT

\title{
Respiratory chain complex $V$ deficiency due to a mutation in the assembly gene ATP12
}

\author{
L De Meirleir, S Seneca, W Lissens, I De Clercq, F Eyskens, E Gerlo, J Smet, R Van Coster
}

J Med Genet 2004;41:120-124. doi: 10.1136/jmg.2003.012047

In patients with mitochondrial encephalomyopathies an increasing number of causative gene defects have been detected. The number of identified pathogenic mitochondrial DNA mutations has largely increased over the past 15 years. Recently, much attention has turned to the investigation of nuclear oxidative phosphorylation (OXPHOS) gene defects. Within the OXPHOS defects, complex $V$ deficiency is rarely found and, so far, these defects have only been attributed to mutations in the mitochondrial MTATP6 gene.

Mutation analysis of the complete coding regions at the cDNA level of the nuclear ATP11, ATP12, ATP $\alpha, A T P \beta$ and ATP $\gamma$ genes and the mitochondrial MTATP6 and MTAT8 genes was undertaken in two unrelated patients. Blue Native polyacrylamide gel electrophoresis followed by catalytic staining had already documented their complex $\mathrm{V}$ decreased activity.

Extensive molecular analysis of five nuclear and two mitochondrial genes revealed a mutation in the ATP12 assembly gene in one patient. This mutation is believed to be the cause of the impaired complex $\mathrm{V}$ activity. To our knowledge, this is the first report of a pathogenic mutation in a human nuclear encoded ATPase assembly gene.

$\mathrm{T}$ he respiratory chain/oxidative phosphorylation system consists of five multisubunit complexes, four of which, complexes I, II, III, and IV, cooperate to generate a proton gradient across the mitochondrial inner membrane. Complex V (ATP synthase or ATPase) couples proton flow from the intermembrane space back to the matrix by the conversion of ADP and inorganic phosphate to ATP. ATP synthase comprises an integral membrane component $F_{0}$ and a peripheral moiety $F_{1}$. All five subunits of $F_{1}(\alpha, \beta, \gamma, \delta, \varepsilon)$ and most $\mathrm{F}_{0}$ subunits of the mammalian ATP synthase are nuclear encoded. Only two $F_{0}$ proteins (ATP6 and 8) are encoded by mitochondrial DNA. ${ }^{1}$ Besides the nuclear genes coding for the subunits of the ATPase complex, several assembly genes have been studied in yeast and their human analogues have been described. ${ }^{23}$ Complete loss of the ATP synthase enzyme activity is probably not compatible with life. However, partial loss reflected by a lower amount of functional ATP synthase has been associated with human disease. ${ }^{4}$ This was the case for mutations in MTATP6, a mitochondrial encoded component, which causes ATP synthase deficiency. ${ }^{5}$ No pathogenic mutations involving nuclear encoded subunits have yet been found. We studied two unrelated children with decreased complex V activity and report on a mutation in the ATP12 assembly gene in one patient.

\section{PATIENTS}

Patient 1 was a full-term baby girl, born with a birth weight of $2.550 \mathrm{~kg}$ and head circumference of $30.5 \mathrm{~cm}$, the first child of healthy consanguineous parents of Moroccan origin. Family history was unremarkable.

The girl presented with dysmorphic features, including a large mouth, prominent nasal bridge, micrognathia, rocker bottom feet, and flexion contractures of the limbs associated with camptodactylia. She was hypertonic and did not suck well. The liver was enlarged. Initial investigation including karyotype and skeletal $x$ ray was normal. The kidneys were hypoplastic. Clinically, the presentation resembled COFS (cerebro-oculofacioskeletal) syndrome (Pena-Shokeir type II), except for the absence of microphtalmia and cataracts. Metabolic screening showed increased urinary lactate, fumarate, methylglutaconic acid, and amino acids. In CSF, lactate was $2.9 \mathrm{mmol} / \mathrm{l}$ (normal $<2$ ), pyruvate was normal. In plasma, amino acids were normal but lactate fluctuated between 2.7 and $10 \mathrm{mmol} / \mathrm{l}$ (normal <2.2) and pyruvate between 0.08 and $0.12 \mathrm{mmol} / \mathrm{l}$ (normal $0.03-0.10$ ).

Cerebral magnetic resonance imaging revealed marked cortical-subcortical atrophy, dysgenesis of the corpus callosum with absent anterior genu and rostrum, and hypoplasia of white matter. Within months, the basal ganglia and thalami became atrophic. At the age of 6 months, a muscle and liver biopsy was performed and frozen immediately at $-80^{\circ} \mathrm{C}$. A skin specimen was used for fibroblast culture. The child had a severe developmental delay with seizures and failure to thrive, and died at the age of 14 months from intercurrent infection.

Patient 2 was born at 37 weeks of gestational age from non-consanguineous white parents. A selective caesarian section was performed because of breech presentation. Birth weight was $2.300 \mathrm{~kg}$, height $48 \mathrm{~cm}$ and head circumference $32.7 \mathrm{~cm}$. Apgar scores were 6, 8 and 8 , after 1, 5, and 10 minutes respectively. Within the first day the patient started grunting and required supplementary oxygen. The liver was enlarged. On day 2, a sudden deterioration occurred, with desaturation and poor peripheral circulation necessitating endotracheal intubation, artificial ventilation, and administration of a plasma expander. Cerebral ultrasound showed intraventricular haemorrhage and periventricular hyperechogenic zones. The patient started having convulsions and was treated by intravenous administration of phenobarbital. His blood lactate was $50 \mathrm{mmol} / \mathrm{l}$ (normal $<2$ ). A cardiac arrest necessitated administration of adrenaline and heart massage. Cardiac activity resumed after infusion of sodium bicarbonate. The patient remained hypotensive, had poor peripheral circulation, and dopamine was administered continuously. Ultrasound examination of the heart revealed a small left ventricle. Severe metabolic acidosis persisted despite all efforts to correct it. Following

Abbreviations: BN-PAGE, Blue Native polyacrylamide gel electrophoresis; CRM, cross-reacting material; OXPHOS, oxidative phosphorylation 
another episode of cardiac arrest the patient died on day 3. Immediately post-mortem an autopsy was performed. Skeletal muscle (quadriceps), liver, and heart tissue specimens were taken and frozen in liquid nitrogen. Microscopic studies were not performed. A skin specimen was used for fibroblast culture.

\section{MATERIALS AND METHODS}

Spectrophotometric assays were performed as previously described. ${ }^{6}$ Isolation of mitochondria, solubilisation of oxidative phosphorylation complexes, SDS-PAGE, BNPAGE and catalytic staining were performed as reported. ${ }^{6}$ Total RNA and genomic DNA were extracted from cultured fibroblasts by standard methods. PCR primers were manually designed to cover the complete coding regions at the cDNA level in overlapping fragments of the ATP11, ATP12, ATP $\alpha$, $A T P \beta$, and $A T P \gamma$ genes (GenBank accession numbers AK026004, AF052185, D14710, BC0165512, and NM 005174, respectively). Due to GC rich regions at the 5' end ${ }^{-}$of most of these genes, PCR primers for the genomic amplification of exon 1, and sometimes exon 2, were also designed for most of the genes (GenBank accession numbers AL593856, NT_030843, D28126, M27132, and D16561, respectively). These primers were used for PCR amplification and sequencing of the five genes on an ABI Prism 310 Genetic Analyzer (Applied Biosystems, Foster City, CA, USA). For fragments over $400 \mathrm{bp}$, additional internal sequencing primers were used. (PCR sequences and PCR conditions are electronically available from W Lissens.) To detect the W84R change in exon 3 of the ATP12 gene, PCR primers ATPE3F (5'-GGCTTTGAGATAAACCTGGAC- $\left.3^{\prime}\right)$ and ATP12E3R (5'TCCAGGTTCACACTGTGAAC-3') were used to amplify a $171 \mathrm{bp}$ fragment containing part of exon 3. The W84R change creates a $\mathrm{MnlI}$ restriction site that can easily be detected by digestion of the PCR fragment and analysis on a $15 \%$ polyacrylamide gel.

\section{RESULTS}

In muscle tissue of patient 1 , light microscopy revealed increased lipid content without red ragged fibres. OXPHOS enzymes (I, II, II+III, IV, and V) were measured spectrophotometrically in liver and skeletal muscle. The activity of complex $\mathrm{V}$ was decreased in liver and to a lesser extent in skeletal muscle (table 1). In liver, the activity of complex IV was also decreased. In liver and cultured skin fibroblasts, catalytic staining in the BN-PAGE gel revealed a severe reduction of intensity for complex $\mathrm{V}$ while staining for complex I, II, and IV was normal (fig 1). In skeletal muscle, the staining for complex $\mathrm{V}$ was relatively higher than in liver and cultured skin fibroblasts. Immunoblotting in liver showed a severe reduction of cross-reacting material (CRM) against complex $\mathrm{V}$ using specific antibodies against its subunits $(\alpha, \beta$, and $\delta$ ) (fig $2 \mathrm{~A}$ ), as well as a significant reduction of CRM against the individual complex $\mathrm{V}$ subunits $(\alpha, \beta, d$, and OSCP) (fig 2b). Molecular analysis of the MTATP6 and MTAT8 genes was normal.

Screening different genes coding for ATP synthase subunits $\alpha, \beta$, and $\gamma$ of $\mathrm{F}_{1}$ and assembly gene ATP11 using direct nucleotide sequencing did not reveal any abnormalities. However, in ATP12 a homozygous mutation, TGG $\rightarrow$ AGG, changing a tryptophan to an arginine at position 94 (W94R) was found (fig 3A). Both parents and a healthy sibling were heterozygous for the mutation. The W94R change was not found in 50 controls of healthy patients of Moroccan descent, making a polymorphism unlikely.

In patient 2, biochemical analysis using spectrophotometric methods showed a significantly decreased activity of complex $\mathrm{V}$ in skeletal muscle, whereas the activity of complex IV was at the lower limits of the control range (table 1). In skeletal muscle, heart muscle, and cultured skin fibroblasts, catalytic staining in the BN-PAGE gel revealed a severely decreased intensity of the band corresponding to complex $\mathrm{V}$ and normal intensities of the bands corresponding to complex I, II, and IV (fig l). The amount of complex $\mathrm{V}$ protein was decreased in heart and skeletal muscle as shown by immunoblotting of the complexes separated by BN-PAGE using specific antibodies against several complex $\mathrm{V}$ subunits, whereas CRM for complex III was normal (fig 2A). A significant decrease of several individual subunits of complex $\mathrm{V}$ was also documented (fig 2B). Two dimensional electrophoresis (BN-PAGE/ SDS-PAGE) showed that all major components of complex $\mathrm{V}$ $(\alpha, \beta, \gamma, b$, OSCP, $d)$ could not be visualised in heart muscle from the patient (data not shown). Molecular analysis for mitochondrial DNA mutations in the MTATP6 and MTATP8 subunit genes was negative. Screening genes $\alpha, \beta$, and $\gamma$ of $F_{1}$ ATPase and assembly genes ATP11 and ATP12 did not reveal any mutation.

\section{DISCUSSION}

Mutations have been described in structural subunits of complex $\mathrm{I}^{7}$ and complex II. ${ }^{8}$ Complex III and IV defects are mostly due to mutations in genes needed for the assembly of their subunits. Several mutations in SURF1, SCO1, SCO2, and COXIO are responsible for complex IV disrupted activity, while mutations in the BCSIL gene cause complex III failure in patients. ${ }^{10}{ }^{11}$ Interestingly, Holme described in 1992 the association of methylglutaconic aciduria and ATP synthase deficiency. ${ }^{12}$ The child presented with severe lactic acidosis, hypertrophic cardiomyopathy, and severe mitochondrial ATP synthase deficiency. Methylglutaconic aciduria seems to be a marker of inner mitochondrial membrane dysfunction and can also be seen in other OXPHOS defects. Complex V deficiency is more difficult to detect using spectrophotometric methods but easier with BN-PAGE followed by catalytic staining.

$\mathrm{F}_{0} \mathrm{~F}_{1}$-ATP synthase is comprised of at least fourteen nuclear-encoded subunits and two mitochondrial DNA

Table 1 Activity levels of OXPHOS enzymes in the patients' samples

\begin{tabular}{|c|c|c|c|c|c|c|}
\hline Tissue & Complex I & Complex II & Complex II+III & Complex IV & Complex V & Citrate synthase \\
\hline \multicolumn{7}{|c|}{ Skeletal muscle (mitochondria) } \\
\hline Patient 1 & 134 & 131 & 139 & 541 & 119 & 1011 \\
\hline Patient 2 & 56 & 225 & 200 & 486 & 42 & 471 \\
\hline $\begin{array}{l}\text { Controls } \\
(n=30)\end{array}$ & $\begin{array}{l}115 \\
(39-294)\end{array}$ & $\begin{array}{l}121 \\
(72-338)\end{array}$ & $\begin{array}{l}192 \\
(81-334)\end{array}$ & $\begin{array}{l}939 \\
(491-1888)\end{array}$ & $\begin{array}{l}209 \\
(97-754)\end{array}$ & $\begin{array}{l}1279 \\
(687-2014)\end{array}$ \\
\hline \multicolumn{7}{|c|}{ Liver (mitochondria) } \\
\hline Patient 1 & 42 & 245 & 218 & 150 & 30 & 201 \\
\hline $\begin{array}{l}\text { Controls } \\
(n=30)\end{array}$ & $\begin{array}{l}53 \\
(18-81)\end{array}$ & $\begin{array}{l}194 \\
(87-431)\end{array}$ & $\begin{array}{l}190 \\
(112-289)\end{array}$ & $\begin{array}{l}364 \\
(239-418)\end{array}$ & $\begin{array}{l}87 \\
(35-108)\end{array}$ & $\begin{array}{l}223 \\
(187-359)\end{array}$ \\
\hline
\end{tabular}

Specific activities are expressed as nmoles of substrate $/ \mathrm{min} / \mathrm{mg}$ protein; control values as median (percentile 5-95). 

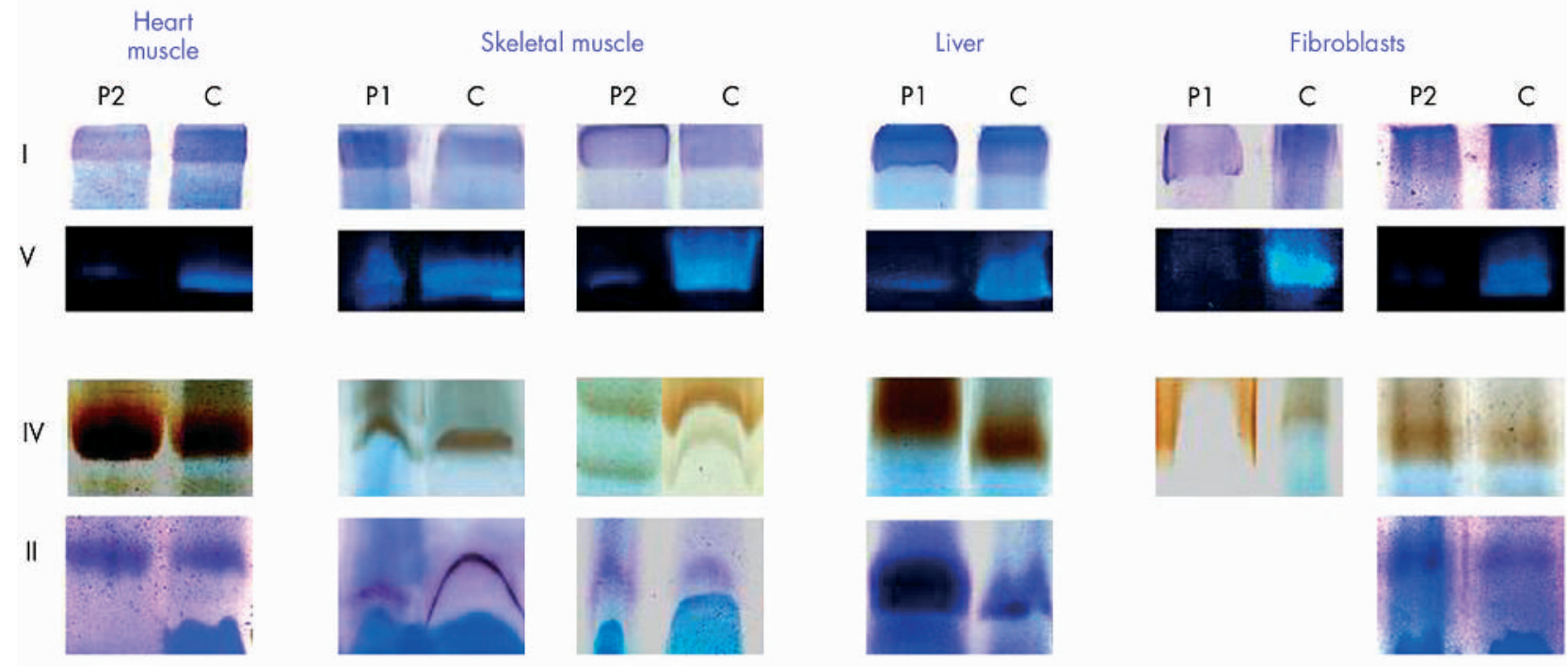

Figure 1 Catalytic staining following separation of the OXPHOS complexes by BN-PAGE showing severely decreased intensities of the bands corresponding to complex $V$ in patients 1 and 2. In skeletal muscle from patient 1 , the intensity of staining for complex $V$ is relatively higher than in liver and in cultured skin fibroblasts. The bands corresponding to complexes I, II, and IV in both patients are comparable to the control.

A

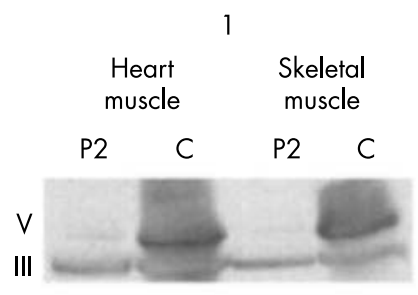

2

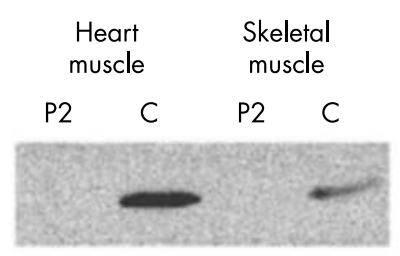

Liver

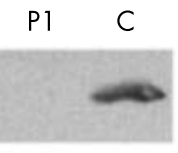

B

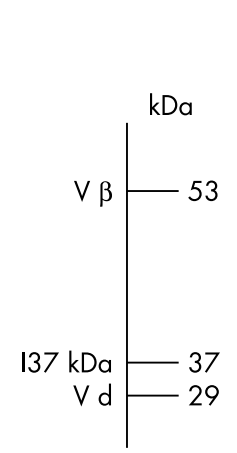

ver

Pl C

$\mathrm{V}$

III

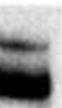

3

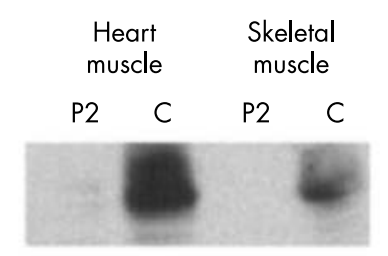

Figure 2 (A) Immunoblotting of complexes III and V following separation by BN-PAGE. Panel 1: a mixture of specific antibodies against the $\alpha$ subunit of complex $V$ and against the core 2 subunit of complex III were used. CRM against complex $V$ was undetectably low in the liver of patient 1 and in heart and skeletal muscle of patient 2, whereas CRM against complex III in both patients was comparable with the control. Panel 2: antibodies were stripped off and the membranes were blotted again using specific antibodies against the $\beta$ subunit of complex $V$. Complex $V$ could not be visualised in the liver of patient 1 or in the heart or skeletal muscle of patient 2. Panel 3: membranes were re-used and blotted with specific antibodies against the $d$ subunit of complex V. Complex V could not be visualised in heart or skeletal muscle of patient 2. (B) Immunoblot visualizing subunits of complex $V$ in liver and heart muscle. Mitochondrial proteins were separated using SDS-PAGE. A significant decrease of CRM for the $\alpha, \beta, d$, and OSCP subunits of complex $V$ is shown in patient 1 and patient 2, compared with the control. CRM for the $37 \mathrm{kDa}$ subunit of complex I in both patients was comparable with the control, as was CRM for the SDHB (Fp) subunit of complex II and subunit 3 of complex IV. 


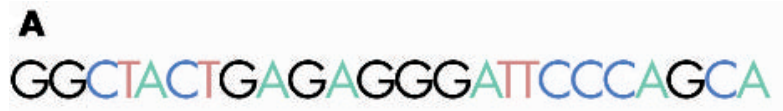

70

80

90
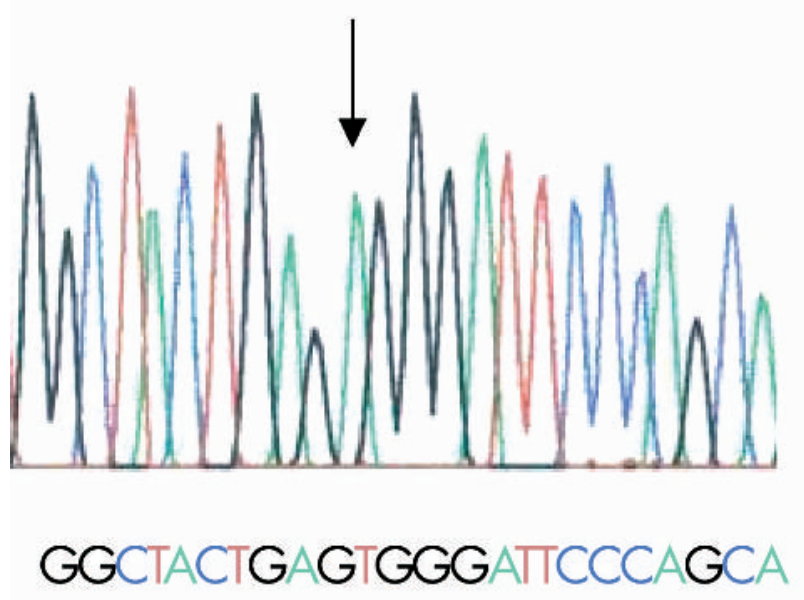

80

90

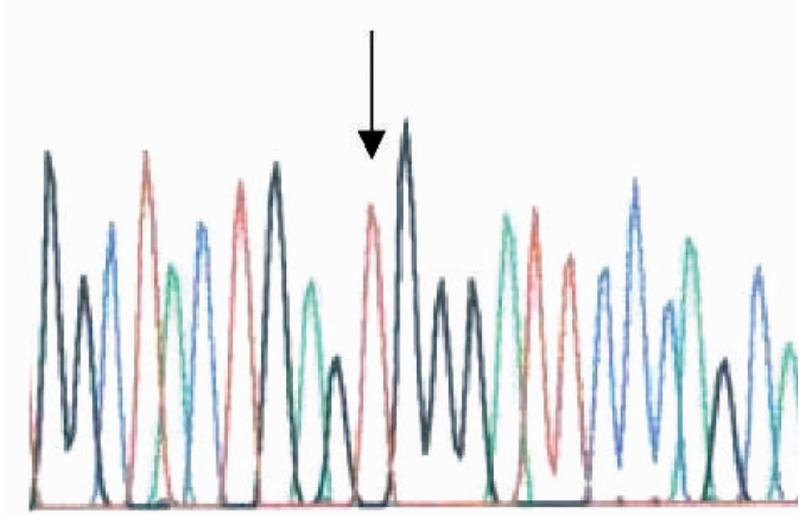

B

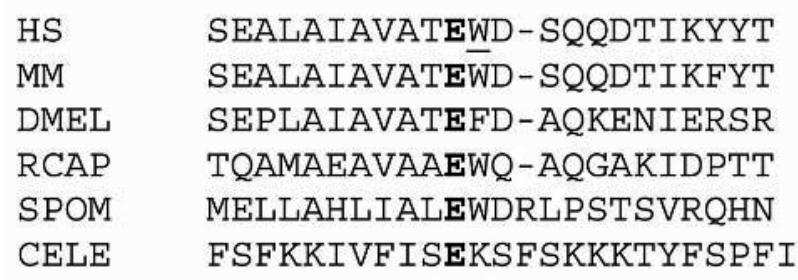

Figure 3 (A) Nucleotide sequence of part of the ATP12 gene. The figure shows the normal sequence in a control sample (bottom) and a homozygous $\mathrm{T} \rightarrow \mathrm{A}$ mutation in our patient (top). (B) Homologous Atpl $2 p$ sequences from Homo sapiens (HS), Mus musculus (MM), Drosophila melanogaster (DMEL), Rhodobacter capsulatus (RCAP), Schizosaccharomyces pombe (SPOM), and Caenorhabditis elegans (CELE). Underlined $W$ is site of mutation, just next to a aminoacid (E) preserved over all species.

encoded subunits. $\mathrm{F}_{0}$, the hydrophobic membrane spanning part is responsible for the $\mathrm{H}^{+}$translocation, while the $\mathrm{F}_{1}$ globular part carries the catalytic domain.

To date, mutations leading to impaired ATPase activity have only been found in maternally inherited mtDNA encoding MTATP6. ${ }^{13}$ The clinical syndrome manifests as NARP (neuropathy, ataxia, retinitis pigmentosa) or the more severe MILS (maternally inherited Leigh's syndrome). Most frequently, these two related mitochondrial disorders are due to a T8993G or T8993C point mutation. ${ }^{14}{ }^{15}$ In one patient with complex $\mathrm{V}$ deficiency presenting in the neonatal period with congenital hyperlactacidaemia, Housteck et $a l^{16}$ showed, using complementation studies, that the defect was located in the nuclear DNA. Electrophoresis and western blot analysis revealed a reduction of complex V whereas the other OXPHOS complexes were present at normal levels. Inspired by the major involvement of assembly genes in complex IV deficiency and failing to find any mutations in the genes $\alpha, \beta$, and $\gamma$, we initiated a mutation analysis of the assembly genes ATP11 and ATP12 in two patients for whom the BN-PAGE gel had shown a severely decreased activity, an indicator of catalytic deficiency.

Like many other mitochondrial proteins, the $F_{1}$ subunits are imported into the matrix compartment as unfolded protein chains. Heat shock proteins HSP60 and HSP10 facilitate their folding. ${ }^{17}$ In Saccharomyces cerevisiae, the final steps in the formation of a fully functional $F_{1}$ require two proteins called Atpl lp and Atpl2p. ${ }^{18}$ It has been shown that they have an essential and indispensable role in the assembly of the $F_{1}$ moiety of the ATP synthase. Yeast mutants that are deficient for either Atpl lp or Atp12p accumulate both the $F_{1}$ and $\beta$ subunits in large protein aggregates inside mitochondria instead of forming the enzyme oligomer. These strains are respiratory deficient and fail to grow on non-fermentable carbon sources. Interestingly, in addition to being ATPase deficient, the mutant strains had lowered activities of cytochrome c oxidase and coenzyme $\mathrm{QH}_{2}$-cytochrome c reductase. ${ }^{2}$ This was also found in our patient. ATPllp was shown to bind the $\beta$ subunit of $F_{1}{ }^{19}$ while ATP $12 p$ interacts specifically with the $F_{1}$ subunit. ${ }^{20}$ These studies provide the basis for a model of $F_{1}$ assembly in which Atp12p is released from the $\alpha$ subunit in exchange for the $\beta$ subunit to form the interhelicase that contains the non-catalytic adenine nucleotide binding site. This binding mechanism is thought to protect the $F_{1}$ subunits from forming non-productive large complexes during the assembly of the enzyme oligomer. ${ }^{1820}$ The human ATPII and ATP12 genes were only recently identified by Wang et al. ${ }^{3}$ The gene products of the human cDNAs act in a manner analogous to their yeast counterparts. Moreover, human ATP12 cDNA complements a yeast $\triangle A T P 12$ disruption mutant. Both the ATP11 and ATP 12 genes are broadly conserved in eukaryotes and are expressed in a wide range of tissues. ${ }^{318}$ ATP12 full length cDNA has been characterised and the gene assigned to chromosome 17p11.2.

The ATP1 1 and ATP 12 assembly factors are not members of the major protein chaperone families (for example HSP60), which work for different substrates. Instead, the action of Atpl $1 p$ and $12 p$ is limited to the biogenesis pathway of the ATP synthase. Neither Atpllp nor Atp12p has a significant homology with other proteins. Elaborated studies of Ackerman and co-workers have already revealed sequence elements in Atp12p that are functionally relevant. Deletion analysis disclosed that some regions could be removed from the mature protein without completely losing the action of $F_{1}$ assembly in vivo. ${ }^{21}$ The functional domain for Atpl2p maps between Asnl81 and Val306 in the carboxyl half of the protein. The terminal 18 amino acids of the protein are involved in oligomerisation with other proteins. The precise role of the amino acids in the domain enclosed by the mitochondrial targeting signal on the left and the functional domain on the right is not clear. Truncated Atp12p proteins, with as many as 180 residues of the amino terminal boundary deleted, but with an intact targeting signal, are still capable of conferring some respiratory activity to the yeast cell. However, it has also been shown that these mutants are temperature sensitive, as the yeast strain is 
completely respiratory deficient at $30^{\circ} \mathrm{C}$ but displays partial respiration function at $23^{\circ} \mathrm{C}$. Missense mutations located in this region in the yeast protein are, unfortunately, not available. ${ }^{21}$ The mutation found in our patient at position 94 lies adjacent to a strongly conserved glutamine conserved in six studied species (fig 3B). ${ }^{18}$ Probably, the Atpl2p activity is severely compromised when a neutral polar amino acid (tryptophan) is changed for a basic one (arginine), and is no longer able to mediate proper $\mathrm{F}_{1}$ assembly.

In conclusion, complex $\mathrm{V}$ deficiency seems to be an early presenting disease in which lactic acidosis, dysmorphic features, and methyl glutaconic aciduria can be major clues in the diagnosis. To our knowledge, his is the first report of complex V deficiency with a mutation in a nuclear encoded assembly gene for ATPase. It is clear that the search for genes causing respiratory chain disorders has only just begun, and many more mutations will be identified in the near future.

\section{ACKNOWLEDGEMENTS}

This work was supported by a grant from the Fund for Scientific Research Flanders, Belgium (FWO Vlaanderen; contract grant number G.0119.02) and from 'KidAuQuai', Ghent, Belgium, and the Association Belge contre les Maladies NeuroMusculaires (ABMM) and Scientific Foundation Willy Gepts, AZ-VUB, and OZR477, OZR887 (Vrije Universiteit Brussel).

\section{Authors' affiliations}

L De Meirleir, Department of Paediatric Neurology, University Hospital Vrije Universiteit Brussel (AZK-VUB), Brussels, Belgium

S Seneca, W Lissens, I De Clercq, Department of Medical Genetics, University Hospital, Vrije Universiteit Brussel (VUB), Brussels, Belgium F Eyskens, Department of Pediatrics and Metabolic diseases, University Hospital, Antwerp, Belgium

E Gerlo, Department of Clinical Chemistry, University Hospital, Vrije Universiteit Brussel (VUB), Brussels, Belgium

J Smet, R Van Coster, Department of Pediatrics, Division of Pediatric

Neurology and Metabolism, Ghent University Hospital, Ghent, Belgium

Correspondence to: $\operatorname{Dr}$ L De Meirleir, Pediatric Neurology, AZK-VUB, Laarbeeklaan 101, B-1090 Brussels, Belgium;

linda.demeirleir@az.vub.ac.be

\section{REFERENCES}

1 Boyer PD. The ATP synthase-a splendid molecular machine. Biochim Biophys Acta 1993:1140:215-50.

2 Ackerman SH, Tzagoloff A. Identification of two nuclear genes (ATP1 1 ATP12) required for assembly of the yeast F1-ATPase. Proc Natl Acad Sci USA 1990;87:4986-90.
3 Wang ZG, White PS, Ackerman SH. Atpl $1 \mathrm{p}$ and Atp $12 \mathrm{p}$ are assembly factors for the F(1)-ATPase in human mitochondria. J Biol Chem 2001;276:30773-8.

4 DiMauro S. Mitochondrial encephalomyopathies. Brain Pathol 2000;10:419-21.

5 Holt IJ, Harding AE, Petty RK, Morgan-Hughes JA. A new mitochondrial disease associated with mitochondrial DNA heteroplasmy. Am J Hum Genet 1990;46:428-33.

6 Van Coster R, Smet J, George E, De Meirleir L, Seneca S, Van Hove J, Sebire G, Verhelst H, De Bleecker J, Van Vlem B, Verloo P, Leroy J. Blue native polyacrylamide gel electrophoresis: a powerful tool in diagnosis of oxidative phosphorylation defects. Pediatr Res 2001;50:658-65.

7 Smeitink J, Sengers R, Trijbels F, van den Heuvel L. Human NADH: ubiquinone oxidoreductase. J Bioenerg Biomembr 2001;33:259-66.

8 Van Coster R, Seneca S, Smet J, Van Hecke R, Gerlo E, Devreese B, Van Beeumen J, Leroy JG, De Meirleir L, Lissens W. Homozygous Gly555Glu mutation in the nuclear-encoded $70 \mathrm{kDa}$ flavoprotein gene causes instability of the respiratory chain complex II. Am J Med Genet 120:13-18.

9 Robinson BH. Human cytochrome oxidase deficiency. Pediatr Res 2000:48:581-5.

10 de Lonlay P, Valnot I, Barrientos A, Gorbatyuk M, Tzagoloff A, Taanman JW, Benayoun E, Chretien D, Kadhom N, Lombes A, de Baulny HO, Niaudet P, Munnich A, Rustin P, Rotig A. A mutant mitochondrial respiratory chain assembly protein causes complex III deficiency in patients with tubulopathy, encephalopathy and liver failure. Nat Genet 2001;29:57-60.

11 De Meirleir L, Seneca S, Damis E, Sepulchre B, Hoorens A, Gerlo E, García Silva MT, Martín Hernandez E, Lissens W, Van Coster R. Clinical and diagnostic characteristics of complex III deficiency due to mutations in the BCS1L gene. Am J Med Genet 2003;120A:13-18.

12 Holme E, Greter J, Jacobson CE, Larsson NG, Lindstedt S, Nilsson KO, Oldfors A, Tulinius M. Mitochondrial ATP-synthase deficiency in a child with 3-methylglutaconic aciduria. Pediatr Res 1992;32:731-5.

13 Nijtmans LG, Henderson NS, Attardi G, Holt IJ. Impaired ATP synthase assembly associated with a mutation in the human ATP synthase subunit 6 gene. J Biol Chem 2001;276:6755-62.

14 Tatuch Y, Pagon RA, Vlcek B, Roberts R, Korson M, Robinson BH. The 8993 mtDNA mutation: heteroplasmy and clinical presentation in three families. Eur J Hum Genet 1994;2:35-43.

15 de Vries DD, van Engelen BGM, Gabreels FJM, Ruitenbeek W, van Oost BA. A second missense mutation in the mitochondrial ATPase 6 gene in Leigh's syndrome. Ann Neurol 1993;34:410-12.

16 Houstek J, Klement P, Floryk D, Antonicka H, Hermanska J, Kalous M Hansikova H, Hout'kova H, Chowdhury SK, Rosipal T, Kmoch S, Stratilova L, Zeman J. A novel deficiency of mitochondrial ATPase of nuclear origin. Hum Mol Genet 1999;8:1967-74.

17 Hendrick JP, Hartl FU. Molecular chaperone functions of heat-shock proteins. Annu Rev Biochem 1993;62:349-84.

18 Ackerman SH. Atpl $1 p$ and Atp 1 $2 p$ are chaperones for $F_{1}$-ATPase biogenesis in mitochondria. Biochim Biophys Acta 2002;1555:101-5.

19 Wang ZG, Ackerman SH. The assembly factor Atpl 1p binds to the beta-subunit of the mitochondrial $\mathrm{F}_{1}$-ATPase. J Biol Chem 2000;275:5767-72.

20 Wang ZG, Sheluho D, Gatti DL, Ackerman SH. The alpha-subunit of the mitochondrial $F_{1}-$ ATPase interacts directly with the assembly factor Atp 12p. EMBO J 2000;19:1486-93.

21 Wang ZG, Ackerman SH. Mutational studies with Atp12p, a protein required for assembly of the mitochondrial $F_{1}$-ATPase in yeast. Identification of domains important for Atp 12p function and oligomerization. J Biol Chem 1998;273:2993-3002. 